\title{
ALGUNOS ASPECTOS COMPARATIVOS DE LAS EMPRESAS EVANGELIZADORAS CATÓLICA Y PROTESTANTE EN AMÉRICA SEGÚN ORTEGA Y MEDINA
}

\author{
Jesús Monjarás-Ruiz' \\ Instituto Nacional de Antropología e Historia. México D.F. México.
}

\section{EL ANDALUZ TRISTE, EL ANDALUZ MEXICANO²}

Don Juan Ortega y Medina (1913-1992), malagueño de nacimiento, transterrado por convicción y mexicano por naturalización, formación, desarrollo profesional y vivencia, si bien nunca rompió con sus raíces peninsulares, siempre buscó y colaboró a explicar lo mexicano.

Para una de sus alumnas, Ortega y Medina:

Fue un espíritu sensible que superó el dolor del pasado y combinó en su carácter una dignidad sobria y un cierto resabio de melancolía. [Por lo cual] Un buen amigo suyo [¿Carlos Bosch García?] lo definió como "el andaluz triste, el andaluz mexicano" (p.13).

Como acertadamente señala Eugenia Meyer:

Ortega el hispano, Ortega el mexicano encuentra su razón y su compromiso de historiador precisamente alli, en la búsqueda de las entreveradas raíces, que paradojicamente son las suyas propias. Lo espaniol, lo americano, la confrontación anglohispana. Las diferencias y las identidades, temas todos que apoyan su trabajo y quehacer cotidiano como maestro y como historiador (p.19). ${ }^{3}$

Durante 43 años, de manera impecable Ortega y Medina dio respuesta al deseo manifestado cuando arribó a tierras mexicanas: 
Desde el punto y hora en que pisé la nuéva y "suave" patria promisoria me juré y me hice el firme propósito de corresponder en la medida de mis fuerzas y de mis capacidades, a la hospitalidad y generosidad de esta para mí tan nueva e inédita España, que pronto sería mi patria de adopción (p.6). ${ }^{4}$

El acercamiento utilizado por Ortega y Medina para, desde su punto de vista, aclarar la problemática de lo que creo se puede llamar su defensa del ser y la cultura hispanas y su incidencia en la mexicana, tuvo dos vertientes. La primera dedicada al estudio de algunos factores básicos de la formación y el devenir histórico estadounidense, a partir del conflicto hispano-inglés en el siglo XVI. La segunda encaminada a indagar, mediante la traducción, análisis y divulgación de la literatura viajera anglosajona sobre México, "virtudes y vicios, perfecciones y defectos" los cuales, si bien producto de una apreciación ajena, para él contribulan a "descubrir y valorar" la esencia de lo mexicano. ${ }^{3}$ Señero de estos campos supo además allegarse un buen número de seguidores.

\section{CONSIDERACIONES GENERALES}

Uno de los problemas que más preocupó al doctor Juan Antonio Ortega y Medina durante su larga trayectoria como investigador fue el de llevar a lo que consideró sus justos términos, las empresas conquistadoras y colonizadoras de los europeos en América.6 Aunque resulta más exacto decir que, en buena parte de sus investigaciones, buscó deslindar las consecuencias de las distintas corrientes de pensamiento y acción que las llevaron a cabo.

Para él, según entiendo, la historia de América a partir de la conquista-colonización europea, primero espaniola y posteriormente francesa y anglo-holandesa, ha sido la del enfrentamiento de dos concepciones y formas de vida diferentes: la católica (iberoamericana) y la protestante (angloamericana) que si bien tuvieron un origen común (la búsqueda de un beneficio espiritual-material), difirieron mucho en cuanto a su desarrollo. Por supuesto lo anterior tuvo validez hasta finales de los años diez del siglo pasado cuando se rompieron los cotos cerrados de influencia ideológica en los países hispanoamericanos.

En el fondo, el origen del problema fue la disputa por la hegemonía mundial entre España e Inglaterra. La que, nos dice Ortega y Medina, prácticamente se resolvió con la pérdida de la supremacía naval de la primera a manos de la segunda. Lo anterior como resultado de dos formas diferentes e irreconciliables de concebir el papel del hombre frente a la Naturaleza. Los españoles la padecerían "alienadamente" en tanto que los ingleses, una vez conocidas sus leyes, la cambiarían y mejorarian: 
El conflicto hispano inglés del siglo XVI por el dominio oceánico fue el de la oposición irreductible de dos programas vitales diferentes; de dos sistemas espirituales distintos; Reforma vs. Contrarreforma, progreso contra tradición, misoneísmo contra modernidad... (p.244).?

Para nuestro autor el proceso evangelizador en América implicó dos utopías: la católica y la protestante. Ambas encaminadas, en cierto momento, a fundar el reino de Dios en la tierra. Así, en su antagonismo teológico reflejarán la competencia colonial, manifestada por medio de la justificación ideológica.

Aunque el arranque del problema, su desenvolvimiento y consecuencias fueron analizados por Ortega y Medina desde diferentes ángulos, para mí es en su libro La evangelización puritana en Norteamérica (Delendi sunt Indi), donde mejor se puede apreciar el trasfondo comparativo de su obra ${ }^{8}$; en él, al precisar los perfiles de la acción protestante en América, hace evidente la validez histórica y sobre todo humana de nuestra, a veces mal entendida y manipulada, mestiza hipanoamericanidad.

En dicha investigación Ortega y Medina se avoca al estudio de lo que se puede llamar el desenvolvimiento americano de la disputa. Esto es, las empresas coloniales, vistas a través del proceso evangelizador, realizadas por católicos y protestantes en América. Fundamentalmente las españolas en la Nueva España y las inglesas en las primeras colonias novoinglesas.

Más que tratar de condenar o de absolver a la evangelización puritana en los actuales Estados Unidos, el autor busca encontrale una explicación racional. Para ello, la sitúa dentro de su contexto para, al ir más allá de lo aparente, llegar a la fuerza motora subyacente de la visible crueldad anglosajona: la concepción anglopuritana de la naturaleza del hombre. Lo que, como contraposición necesaria, lo lleva a explicar con los mismos parámetros, aunque sucintamente, la empresa evangelizadora española.

\section{LA AMBIVALENCIA DEL “SALVAJE" AMERICANO FRENTE AL DETERMINISMO EVANGELIZADOR}

El obligado punto de partida es el encuentro del, para los europeos, Nuevo Mundo, bautizado como América, mismo que revivió entre los navegantes, escritores y filósofos del viejo continente la posibilidad de instrumentar como realidad social el antiguo ideal de una edad dorada, herencia del mundo clásico, en la cual el hombre se encontraría tan cerca de la naturaleza que viviría de lo que ésta buenamente le ofreciera.

Correspondió a la católica España establecer los primeros contactos con los buenos salvajes del tropezado paraíso. Impresión que, más de cincuen- 
ta años de por medio, en un principio no difirió de la captada por los anglosajones y franceses en sus primeros encuentros con los nativos americanos. Visión id́lica que abarcó no sólo a los habitantes, sino también a los territorios hallados. Lo que en los salvajes era bondad, fue fertilidad y riqueza en la tierra por ellos ocupada.?

Para los ingleses en su primer contacto, los pieles-rojas (menos recolectores-cazadores y mucho más agricultores de lo que se había pensado) representaron la pureza de la naturaleza humana frente a la decadencia europea. Imagen plasmada, desde su idealizado punto de vista, en dibujos, grabados y acuarelas. Interpretación que, sin perder cierto valor antropológico transportaba, apartándolo de su realidad, al indígena norteamericano a mundos romanos o renacentistas. Visión tendiente a provocar ansias colonizadoras en los pobladores ingleses del viejo continente mismas que, de paso, despertaban sentimientos antiibéricos; al realzar idealmente la figura de los nativos, se exacerbaba el papel de verdugos achacado a los españoles. Inspirados en algunos escritos de fray Bartolomé de las Casas, particularmente en su Breve relación de la destrucción de las Indias Occidentales, los grabados que acompañaron su edición alemana, fueron las armas más comunes esgrimidas en contra de España, incluso ya a finales del siglo XIX ${ }^{10}$. Sin embargo, a pesar de su imaginaria belleza, dicha visión estética contribuyó muy poco a la salvación del indio norteamericano.

Tanto aquí como en otros estudios, considero que Ortega y Medina deja entender que, con la creación, propagación y pervivencia de la "leyenda negra española", independientemente de su razón o sinrazón de ser, todo los países colonialistas se abrogaron moral y éticamente el derecho a justificar sus iguales o peores atrocidades en contra de los pueblos inhumana e injustamente sojuzgados.

Al comparar las representaciones inglesas de los así llamados pielesrojas con las españolas de los indígenas mesoamericanos, Ortega y Medina considera que, en ellas se hacen evidentes las ideas rectoras de dos mundos en conflicto. Por un lado el espaniol-católico-tradicional con elementos medievales pseudorenacentistas, pero también prehispánicos, (incluyenteuniversalista), frente a la visión protestanté-anglosajona, únicamente nórdicorenacentista (excluyente-individualista), sin elementos indígenas americanos. Problemática surgida a inicios del siglo XVI con el enfrentamiento reformista-contrarreformista que, como lo expresa Carlos Bosch, produjo el gran cisma eclesiástico: “...cuya consecuencia fue la victoria de la modernidad protestante y burguesa británica, al enfrentarse a la postura católica y misoneísta hispánica" (p.3)." 
Idílica primera impresión de los ingleses que pronto se deterioró transformando en su desgaste al buen salvaje en un bárbaro cualquiera. (Igual que pasaría a los españoles cuando se enfrentaron a los indígenas extramesoamericanos). Frente a la visión paradiśaca se encontraba la concepción históricoteológica del protestantismo anglosajón, inspirada en las sagradas escrituras y fuente de validación de sus acciones. A su destrucción mucho contribuyó también la negativa de los pieles-rojas a seguir alimentando a los ingleses con la esperanza de que se marcharan. Lo que hizo repensar a éstos el papel al que estaban predestinados en su nuevo mundo, desde luego, para ellos, más rico y prometedor, tanto en recursos naturales como humanos, que el conquistado y colonizado por los españoles. Idea, la de imitación-competencia-superación, activadora subyacente de las empresas europeas en Africa y en América. ${ }^{12}$

En el siglo XVI tres fueron los objetivos perseguidos por los ingleses en América: uno económico que les permitiera cultivar productos obtenidos a altos precios en el sur de Europa; otro político-estratégico encaminado a desbaratar al comercio español ultramarino, mismo que redundaría en la liberación de Inglaterra de la amenaza hispana y, un tercero y último espiritual que buscaba la salvación cristiana del indio; por diferentes razones, sobre todo en lo que toca a la tercera de las metas, la empresa fracasó.

Como lo señala el autor en otro lugar, en lo que se refiere a los dos primeros objetivos:

... el éxito del protestantismo se debió en buena parte al nuevo escenario oceánico en el que pudieron fervorosamente ejercitar los protestantes la nueva fe religiosa, náutica y mercantil. Desde la época de [sir Francis] Drake los campos quedaron deslindados: a la España Católica quedó reservado el mando continental y el predominio militar de sus tercios, durante el siglo XVI; a la Inglaterra el domino en el mar y a la larga el universal, siglos XVIII y XIX (p.237). ${ }^{13}$

Para Ortega y Medina en el siglo XVII el panorama cambió merced al nuevo tipo humano que intentó la tarea y que trasplantó, con su modernidad, la crueldad basada en la idea, corriente en ese entonces, de que el sometimiento de una nación conquistada tenía que hacerse por medio del temor y no por el del convencimiento. Pensamiento expresado en la aplicación americana de la frase "el mejor irlandés (es) el irlandés muerto", de esta forma para los ingleses "el mejor indio (fue) el indio muerto".

Lo prometedor del nuevo intento radicaba en que las relaciones entre pieles-rojas y caras-pálidas quedaron sancionadas por un pacto en el cual, a cambio del trabajo de los primeros, los ingleses se comprometian a gobernar, defender y sobre todo a darles a conocer "la palabra de Dios de acuerdo 
con el contenido bíblico". Asimismo en dicho arreglo, se consideraba la posibilidad de celebrar contratos de compra-venta de tierras. O sea que se cambiaban temporalidades por espiritualidades. Sin embargo las desiguales concepciones legalistas de pieles-rojas e ingleses entrañaban un equívoco, los segundos compraban tierras, los indígenas creian vender el derecho al uso de las mismas. De hecho la posesión de la tierra, o mejor dicho, la eficiente y exhaustiva explotación de ésta según los postulados angloprotestantes, fue la causa de todas las guerras antiindias encaminadas a despojar a los pieles-rojas de sus heredades.

Los puritanos novoingleses, siguiendo a Calvino, consideraban al ser humano como uno fundamentalmente pecaminoso y depravado, determinismo teológico del que sólo podían salvarse uno cuantos elegidos por predestinación divina, idea que se complementaba con la teoría de la vocación o calling, basada en el autoanálisis que llevaba a determinar para qué lo había hecho a uno Dios útil, la cual "cubría y orientaba todas las actividades humanas". Determinismo teológico que, años más tarde se convertiría en el "Destino manifiesto" estadounidense. ${ }^{14}$ Frente a tal doctrina el piel-roja se encontró carente de posibilidades para formar parte del mundo puritanoanglosajón. Con el paso del tiempo se suavizó la dureza dogmática puritana. Sin embargo, para los indígenas norteamericanos la tolerancia resultó tardía, pues al haber sido virtualmente aniquilados ésta poco les preocupó.

Según lo señala Ortega y Medina, en esta etapa, al lado de los seguidores del determinismo dogmático puritano existieron personas de la talla de un Roger Williams, que buscaba un camino de integración entre ingleses y pieles-rojas, mediante la adopción de una forma sui generis de cristianismo más acorde con su nivel de desarrollo sociopolítico y la forma de vida derivada de éste.

Lo dicho no quiere decir, como lo muestra el párrafo anterior, que no hubieron intentos de convivencia pacífica, sin embargo, por encima de éstos, se encontraban por un lado las desbordadas pretensiones inglesas que implicaban la aniquilación del mundo piel-roja y, por el otro, el esfuerzo de algunos grupos indígenas que, en un desesperado intento, pugnaron por conservar su antiguo y propio sistema de vida. Enfrentamiento que no fue sólo el de dos razas distintas sino el de dos concepciones diferentes de la vida.

\section{¿INTEGRACION CONTRA ELIMINACION?}

En forma comparativa Ortega y Medina considera que los españoles lograron buena parte de lo que se propusieron al incorporar en gran medida 
al indio a la cultura cristiana, caso contrario de lo sucedido con los afanes anglosajones. Lo que de ninguna manera obedeció a una falta de esfuerzos; afirmación que implica un rechazo a la conseja de que los anglosajones no intentaron salvar al indio mediante la evangelización. Los resultados obtenidos tuvieron que ver, más que con los hombres que lo intentaron, con las ideas que estaban detrás de ellos. Los católicos adaptaron su método a la realidad encontrada; los puritanos hicieron lo contrario.

Asimismo, de acuerdo con Ortega y Medina, es necesario considerar la diferencia fundamental que significó el que la empresa española tuviera por cabeza a la Corona, a diferencia de las inglesas que más bien asumieron el carácter de empresas privadas, lo que imposibilitó que el indio norteamericano contara con la aleatoria ventaja que representaba el ser súbdito de un poder político central. A lo que hay que agregar que en los intentos ingleses el interés mercantil se sobrepuso al religioso. Aunque matizando, el último argumento también podría aplicarse, sobre todo, a las primeras expediciones descubridoras-conquistadoras españolas.

Los católicos buscaban la integración; los protestantes, por motivos teológico-racistas, permanecieron alejados tanto en el aspecto religioso como en el humano. Entre ingleses y pieles-rojas no existieron, en general, ni mestizaje biológico ni un proceso de aculturación (en ciertos aspectos interactivo), lo que mucho tuvo que ver con su fracaso. En otras palabras, para Ortega y Medina incluso desde muy temprano, el español se sintió y, en buena medida, se volvió americano; por su parte los ingleses carecieron de americanidad. O sea que el camino seguido por los protestantes, no obstante tender teóricamente a la redención-asimilación del indio norteamericano, la falta de voluntad de éste, según los puritanos, lo condenaba a la destrucción, por encima de los esfuerzos de algunos bien intencionados evangelizadores protestantes (de entre los cuales destaca John Eliot), que pugnaron porque los ingleses cumplieran su misión; argumentando incluso que se hiciera, simplemente para evitar parecerse a los crueles e injustos españoles.

Destrucción del indígena norteamericano la cual, a pesar del intento -dramático por fallido- de salvarlos, molesta ahora a nuestros vecinos ya que también implica la destrucción de sus raíces americanas. Hoy en día, a pesar de que buscan tranquilizar sus conciencias levantando estatuas en honor de sus héroes indios, todavía no se deciden a integrar a su ser histórico los restos de las culturas que podrían darles su americanidad, más que perdida, nunca encontrada. ${ }^{15}$ 


\section{CONSIDERACIONES FINALES}

Creo que de este esbozo de algunos aspectos comparativos de la obra de Ortega y Medina puede adelantarse la hipótesis de que si bien, para él, en Hispanoamérica, (en este caso particularmente en lo que hoy es la República Mexicana), la conquista y colonización españolas no estuvieron exentas de crueldades y abusos, éstas produjeron, en general, una mezcla biológica y cultural que dio por resultado el surgimiento de nuevas y propias manifestaciones culturales, plasmadas en diversas nacionalidades a partir de las luchas independentistas. Las cuales, en lo que a su trasfondo se refiere, más que buscar su sobrevivencia en uno u otro de los extremos, tienen su fuerza en la simbiosis de sus raíces, españolas e indígenas. ${ }^{16}$

\section{NOTAS}

1 Como un pequeño homenaje dedico la presente ponencia a la memoria del doctor Juan Antonio Ortega y Medina quien tuvo diferentes e importantes significaciones en el transcurso de mi vida. Fundamentales fueron su discreta guía y orientación que mucho me ayudaron a desentrafiar mi, creo, verdadera vocación y, ya en el ejercicio profesional, importantes fueron sus sugerencias y correcciones amén de sus enseñanzas formales en cursos y seminarios. Aunque por encima de todo, lo mejor fue el entrafiable afecto que me dispensó durante más de cuarenta años. Mi intervención únicamente busca establecer lo que considero fueron sus puntos de vista sobre el tema dentro de sus propios términos. Mucho agradezco las sugerencias que me hicieron mis amigos y colegas Rosa Camelo, Gabriel Moedano Navarro, Rafael Tena y Susana Cuevas para la versión final de este trabajo. También doy las gracias a la senora Yolanda Torres y al sefior Francisco J. Peral Rabasa por su apoyo secretarial.

2 Mayer, Alicia, "Semblanza de Juan A. Ortega y Medina (1913-1992)", en Históricas, 36, Boletín del Instituto de Investigaciones Históricas (IIH) de la Universidad Nacional Autónoma de México (UNAM), (Número en Homenaje a Juan A. Ortega y Medina), México, 1992, pp. 11 16.

3 Meyer, Eugenia, "El Nacionalismo como objeto de conciencia en la obra de Ortega y Medina", en Historicas, 36, Boletín del IIH de la UNAM, (Número en Homenaje a Juan A. Ortega y Medina), México, 1992, pp. 17-23.

4 Ortega y Medina, Juan Antonio, "Autobiografia. Espíritu y vida en claro", en Históricas, 36, Boletín del IIH de la UNAM, (Número en Homenaje a Juan A. Ortega y Medina), México, 1992, pp. 6-10.

5 Ortega y Medina, Juan Antonio, México en la conciencia anglosajona Vol. 1, Porrúa y Obregón, S. A., México, 1953 (Colección México y lo mexicano). Véase en especial el "Prólogo".

6 Sobre el particular véase: O'Gorman, Edmundo “De Ave Fénix". Respuesta al discurso de ingreso del doctor Juan Antonio Ortega y Medina a la Academia Mexicana de la Historia en Memorias de la Academia Mexicana de la Historia, t. XXX (1971-1976), México, pp. 252-258. Entre otras cosas, al referirse a los intereses académicos de Ortega y Medina, don Edmundo O'Gorman señala: “...sobre todo, la gran querella anglohispánica de los siglos XVI y XVII ha sido motivo, por parte de Ortega, de originales abordajes que incluyen estudios sobre la Reforma $y$ Contrarreforma, la evangelización puritana en la Nueva Inglaterra y otros aspectos del adveni- 
miento de la modernidad proyectado en el horizonte del tradicionalismo hispánico y su reflejo en el Nuevo Mundo" (p.253).

7 Ortega y Medina, Juan Antonio, "De Andrenios y Robinsones". Discurso de ingreso a la Academia Mexicana de la Historia en, Memorias de la Academia Mexicana de la Historia t. XXX (1971-1976), México, pp. 216-251.

8 Ortega y Medina, Juan Antonio, "La evangelización puritana en Norteamérica. Delendi sunt Indi, prólogo de Leopoldo Zea, Fondo de Cultura Económica (FCE), México, 1976, (Colección Tierra Firme). A menos que se indique lo contrario, el desarrollo del texto corresponde a dicho libro.

9 El tema de la dicotomía conceptual entre el indio bondadoso, manso y por ello explotable frente al indio salvaje, perverso, feroz y en consecuencia combatible y extinguible lo retomó Ortega y Medina en su libro Imagologia del bueno y del mal salvaje, UNAM-IIH, México, 1987. En él analiza los puntos de vista de los que considera los principales autores nacionales o extranjeros que se han ocupado del tema. En el fondo, su estudio es una defensa justificatoria del papel desempeniado por España en el sojuzgamiento y reparto del resto del planeta que formó y forma la esfera de influencia del mundo occidental, originalmente europeo y actualmente, en su versión americana, básicamente estadounidense.

10 En particular los grabados del flamenco Theodor De Bry, quien también había realizado grabados de los dibujos y acuarelas de los artistas que tomaron parte en las primeras expediciones protestantes (francesas e inglesas) a América, a saber: Jacobo Le Moyne y John White. Desde el punto de vista artístico conceptual a los grabados de De Bry se contraponen los del hispano fray Diego Valadés.

11 Bosch Garcla, Carlos, "Prólogo" a El conficto anglo-español... La ficha completa aparece en la siguiente nota.

12 El tema, referido básicamente a la supremacía naval, lo abordó Ortega y Medina en su libro $E l$ conflicto anglo-español por el dominio oceánico, UNAM, IIH, México, 1981, con una segunda edición, prologada por Carlos Bosch García, de Editorial Algazara, Málaga, Espania, 1992.

13 Ortega y Medina, Juan Antonio, "De Andrenios y Robinsones..."

14 Mismo que, como doctrina, nos dice Ortega y Medina: "...no es estrictamente norteamericano supuesto que sus antecedentes históricos y religiosos conformativos se remontan al siglo XVI, durante el cual estalla el conflicto entre el misonelsmo contrarreformista espanol y la modernidad reformista (anglicano-puritana) británica..." p.10. Ortega y Medina, Destino Manifiesto. Sus razones historicas y su ratz teologica. SepSetentas, 49, México, 1972.

15 Otro aspecto, o tal vez el origen del problema lo trató Ortega y Medina en: "Monroísmo arqueológico. Un intento de compensación de americanidad insuficiente", en Cuadernos Americanos, año XII, número 5 (septiembre-octubre), Editorial Cultura, México, 1953, pp. 168-189. Aqui, tomando como base las obras de John Lloyd Stephens (Incidents of Travel in Central America, Chiapas and Yucatan e Incidents of Travel in Yucatan, publicadas en 1841 y 1843 respectivamente), deja en claro que el "vuelco americano" de la anticuaria estadounidense, ocupada hasta cerca de 1841 fundamentalmente en Egipto, significó el establecer por un lado la independencia del desarrollo cultural mesoamericano, en especial el del área maya, $y$, por el otro, poder enfrentar a Europa y el resto del mundo antiguas y altas culturas americanas (si bien no en los Estados Unidos sí en el continente) equiparables a las de cualquier parte del orbe, en especial las mediterráneas.

16 Resulta importante indicar que el propósito de Ortega y Medina en las obras sefialadas, particularmente en La evangelización puritana... fue el de estudiar las ralces, la instrumentación y las consecuencias de las empresas conquistadoras y evangelizadoras, espafiola e inglesa, en las poblaciones nativas americanas. O sea el binomio indígenas-europeos; lo que evidentemente excluye la participación de los africanos y asiáticos incorporados durante la época colonial. 